\title{
Continuing Education
}

\section{Getting Quality for the Price}

An important issue in the area of continuing education concerns the proliferation of specialized short courses, institutes, preconferences, or workshops that have been set up just for librarians and slanted toward what the organizers perceive to be specialized needs of librarians or current topics that are likely to attract librarians. I am not sure that this is the best way to meet the continuing education needs of librarians.

Within reason, most of us are able to obtain released time for those continuing education activities that we wish to attend. Others have dealt with the problems of abuse of released time or of staffing when too many want to be gone at the same time. Those issues will not be dealt with here. For the individual who wants to attend continuing education activities, then, the investment of time is usually not difficult or burdensome. The investment of money, however, both in terms of course fees and any travel or lodging expenses involved, can often be quite expensive. Some recent examples of course fees from the continuing education opportunities listing in CoRL News include $\$ 455$ for three days, $\$ 295$ for seven days, $\$ 200$ for three days, and $\$ 150$ for four days. Travel, food, and lodging are usually involved, too, especially for those who do not live in large metropolitan areas.

With the financial difficulties that most libraries have, few administrators have the money to help or encourage members of the staff to attend expensive workshops or courses. And, with most of us receiving salaries that are less than generous, few librarians are able to finance the registration fees as well as the other expenses that would be incurred for even one of the more expensive workshops per year. The fact that travel and other expenses keep increasing means a considerable outlay even for a modestly priced workshop or course.

For those who have the means to attend specialized continuing education offerings, there is the issue of whether or not they are getting a fair return on their investment. Most of us have been to enough in-service programs, preconferences, workshops, or other programs to know that often we do not benefit enough to justify the expense of either time or money, let alone both.

While there is little that can be done about the high cost and/or expense involved in attending many of the continuing education programs, it is possible to ensure better quality by setting up an accreditation or approval procedure that would in some ways judge the proposed program before it was listed in ALA publications. Should a proce- dure be formalized for assigning CEU's, an accreditation or approval evaluation could be part of the process. Nevertheless, an accreditation process would be time-consuming and difficult, even if tied into the granting of CEU's, and thus is not a likely solution to the problem.

A very viable alternative to the extraordinary expense or all too often poor quality of many continuing education programs is to take formal academic courses offered by colleges or universities. Certainly many of us have been disappointed by college courses we have taken. On the whole, however, I have found that I have been much more successful in selecting academic courses that have met my needs and interest and have been worth the time and expense than I have been in finding good continuing education programs.

All too often, it seems that some of the continuing education programs are too superficial or too brief to really do much good. As an example, some of the recent rash of statistics for lihrarians courses have been so watered down and have covered so few topics that little is gained from them. Anyone who wanted to learn some statistics would be much better off to take an academic course in statistics. While the investment of time and the work one would have to do is much greater, the knowledge gained would be much more useful.

The quality of continuing education programs needs to be improved so that the value derived from them is equal to the expense involved. Until that happens, I would strongly advise against attending many of them.-Stella Bentley.

Editor's Note: Stella Bentley is reference librarian, Education Library, Indiana University. Bloomington.

\section{Western European Specialists}

The Western European Specialists Section (WESS) will vote on the proposed bylaws of the section during the WESS business meeting Tuesday, July 1, 11:30 a.m. to 12:30 p.m. at the New York Conference. The section published the proposed bylaws in the November issue of CURL News (p.322-23). WESS members are encouraged to review the proposed guidelines before the meeting. 